\title{
IMPROBIDADE ADMINISTRATIVA: UMA REVISÃO INTEGRATIVA DA LITERATURA NACIONAL E INTERNACIONAL
}

\author{
Francileyde Sebastiana Rangon, Erika Mayumi Kato Cruz, Marco Antonio Catussi Paschoalotto \\ Universidade do Oeste Paulista - UNOESTE, Curso de Administração, Presidente Prudente, SP, E-mail: \\ fran.rangon@gmail.com
}

\begin{abstract}
RESUMO
É de amplo conhecimento que durante toda a história da humanidade, a corrupção já acontecia através de governantes que usurpam ou desviam verbas públicas para o seu proveito próprio. Assim, o objetivo deste trabalho é analisar trabalhos já existentes acerca do tema Corrupção, Improbidade Administrativa no Brasil e fora dele. Para atingi-lo, utilizou-se de uma revisão integrativa na literatura em cinco áreas, sendo estas: Improbidade Administrativa; Corrupção; A Lei 8.429/92; Probidade e Moralidade. Como resultado, foram elaborados cinco quadros demonstrando um resumo dos principais estudos de cada uma das cinco áreas analisadas. Estes demonstraram que a corrupção parte do ato de desonestidade, imoralidade e improbidade em relação aos bens de uso comum, sendo estes atos cabíveis de punição perante a Lei 8.429/92. Conclui-se o objetivo deste estudo e disponibiliza sua contribuição para novas pesquisas e favorecimento na busca por novas soluções no combate e/ou controle a este mal atual.
\end{abstract}

Palavras-chave: Administração Pública. Improbidade Administrativa. Corrupção.

\section{ADMINISTRATIVE IMPROBITY: AN INTEGRATING REVIEW OF NATIONAL AND INTERNATIONAL LITERATURE}

\begin{abstract}
It is widely known that throughout the history of mankind, corruption was already happening through rulers who usurp or divert public funds to their own advantage. Thus, the objective of this work is to analyze existing works on the topic Corruption, Administrative Misconduct in Brazil and beyond. To achieve this, an integrative review was used in the literature in five areas: Administrative Improbity; Corruption; Law 8.429 / 92; Probity and Morality. As a result, five tables were prepared summarizing the main studies of each of the five areas analyzed. These have demonstrated that corruption starts from the act of dishonesty, immorality and impropriety in relation to goods in common use, these acts being punishable under Law 8.429 / 92. The objective of this study is concluded and provides its contribution to new research and favoring the search for new solutions in the combat and / or control of this current evil.
\end{abstract}

Key words: Public Administration. Administrative Improbity. Corruption. 


\section{INTRODUÇÃO}

A improbidade administrativa ocorre, quando o agente, independentemente da sua função, não cumpre com os princípios que norteiam a administração da organização na qual faz parte e não se intimidam com as penalidades cabíveis na Lei, e abusa de forma ilícita e imoral dos recursos em benefício próprio. Já a lei de Improbidade Administrativa disciplina sanções aplicáveis aos agentes públicos nos casos do enriquecimento ilícito, violação dos princípios da administração pública e danos ao erário. O objetivo desta lei é a proteção da administração na maior e melhor forma possível, como meio principal de evitar a corrupção.

Ampliando essa visão, a introdução da palavra corrupção no estudo da improbidade nos traz o benefício de melhor demonstrar como se ocorre e como se combate à improbidade. Notase então que a corrupção está ligada com questões que envolvem problemas na legalidade, bom andamento e correção dentro das instituições e seus funcionários. É imposto, um enfrentamento desta corrupção nas políticas públicas institucionais, restaurando de forma mais efetiva e transparente os valores e princípios outrora estabelecidos.

Apesar de ser um tema de extrema importância nacional a internacional, no ramo da administração pública a improbidade administrativa e a corrupção são poucos estudados, ao passo de obterem estudos muito mais ligados ao direito administrativo do que na administração pública.

Com esse embasamento se pode chegar a seguinte questão problemática: Como a corrupção e a improbidade administrativa são estudadas nacional e internacionalmente?

Para solucionar esta problemática, este artigo tem como objetivo geral analisar trabalhos já existentes acerca do tema Corrupção, Improbidade Administrativa no Brasil e fora dele e assim contribuir para estudos futuros. Como objetivos específicos, pretende-se: Descrever os estudos realizados sobre Corrupção e Improbidade Administrativa no Brasil; descrever também os estudos realizados sobre Corrupção e Improbidade Administrativa internacionalmente; analisar as relações entre a bibliografia nacional e internacional.

Assim, este estudo justifica-se devido à importância prática que os temas vêm ganhando no dia-a-dia, para seu melhor entendimento, assim como na teoria, em ser um marco na administração pública para outros estudos sobre a área, relacionados aos conceitos de improbidade administrativa e corrupção no Brasil e fora dele.

\section{MÉTODOS}

Um dos métodos adotados será a pesquisa qualitativa que, segundo Richardson (2007) é fundamentada em análises qualitativas, caracterizando-se, pela complexidade da análise, compreensão e classificação dos processos vividos e estudados, não se utilizando de instrumentos estatísticos na análise dos dados. Esse tipo de análise tem por base conhecimentos teóricoempíricos que permite atribuir-Ihe cientificidade.

Quanto aos procedimentos para coleta e análise dos dados, adotaremos a pesquisa bibliográfica que, para Gil (2007) se fundamenta a partir do conhecimento disponível em fontes bibliográficas, principalmente livros e artigos científicos.

A pesquisa bibliográfica ou de fontes secundárias é a que especificamente interessa a este livro. Além disso, Gil (2007) nos deixa claro que a escolha deste tipo de pesquisa tem como vantagem, permitir ao investigador a cobertura de uma gama de fenômenos muito mais ampla do que aquela que poderia pesquisar diretamente.

Para análise dos dados utilizou-se da revisão integrativa, que para Botelho (2011) é um método específico, que resume o passado da literatura empírica ou teórica, para fornecer uma compreensão mais abrangente de um fenômeno particular. Portanto, neste estudo foi utilizado em seu desenvolvimento revisão da literatura e revisão integrativa, uma vez que este possibilita a síntese e análise do conhecimento científico já produzido sobre o tema abordado. 


\section{RESULTADOS}

Os resultados obtidos neste artigo foram tabulados nos quadros a seguir, de forma a facilitar o entendimento e a contribuição de cada estudo para o desenvolvimento da área, assim como descrever o estudo sobre a Corrupção e a Improbidade Administrativa nacional e internacionalmente.

Abaixo, podemos ver e compreender o resultado da pesquisa realizada sobre este tema em estudo: 
Quadro 1. Improbidade Administrativa

\begin{tabular}{|c|c|}
\hline ESTUDO REALIZADO & RESUMO \\
\hline Cossatis, R.C, (2010) & $\begin{array}{l}\text { Em seu artigo, mostra que a prática do ato de improbidade aciona uma série } \\
\text { de sistemas e microssistemas que, conjugados, visam a coibir essa violação à } \\
\text { Constituição e aos princípios por ela elencados, o que significa dizer que será } \\
\text { acionado o sistema penal. }\end{array}$ \\
\hline Costa, H.P, (2005) & $\begin{array}{l}\text { Humberto Pimentel Costa tem um bom esclarecimento sobre a corrupção } \\
\text { ligada à improbidade onde, diz que a introdução da palavra corrupção no } \\
\text { estudo da improbidade administrativa tem uma finalidade útil. O termo, } \\
\text { entre os autores de formação não jurídica, é mais encontradiço do que a } \\
\text { expressão improbidade. }\end{array}$ \\
\hline Costa, L.C. P, (2014) & $\begin{array}{l}\text { Costa nos apresenta em seus ensinamentos que apesar de gozarem de } \\
\text { direitos fundamentais por também serem cidadãos, direitos como a } \\
\text { intimidade, a privacidade, os agentes públicos podem até praticar atos } \\
\text { imorais, desde que os mesmos não invadam os limites da ética privada, } \\
\text { entretanto, sob a ótica da ética pública, onde se é analisada a improbidade } \\
\text { administrativa, o não cumprimento de valores inerentes à Administração } \\
\text { Pública e aos serviços públicos é que o caracterizaria como ímprobo. }\end{array}$ \\
\hline Crivellaro, G (2002) & $\begin{array}{l}\text { Crivellaro conceitua o ato de improbidade administrativa como todo aquele } \\
\text { praticado por agente público, contrário às normas da moral, à lei e aos bons } \\
\text { costumes, com visível falta de honradez e de retidão de conduta no modo de } \\
\text { agir perante a administração pública direta, indireta ou fundacional } \\
\text { envolvidas pelos Três Poderes. }\end{array}$ \\
\hline Moraes, A, (2012) & $\begin{array}{l}\text { Moraes nos traz que a conduta do administrador público em desrespeito ao } \\
\text { princípio da moralidade administrativa enquadra-se nos denominados atos } \\
\text { de improbidade, previstos pelos artigos da Constituição Federal, e } \\
\text { sancionadas. }\end{array}$ \\
\hline Moura, C.C. S, (2014) & $\begin{array}{l}\text { O autor nos explica que, seguindo os termos da Lei, podem praticar } \\
\text { Improbidade Administrativa: agentes públicos, que considerados todos } \\
\text { aqueles que, definitiva ou transitoriamente, com ou sem remuneração, por } \\
\text { eleição, nomeação, designação, contratação, ou seja, qualquer forma de } \\
\text { investidura ou vínculo exerce alguma função pública (mandato, cargo, } \\
\text { emprego) em nome dos sujeitos passivos do ato de improbidade. }\end{array}$ \\
\hline Paié, K.S. N, (2011) & $\begin{array}{l}\text { Paié nos mostra que combater a improbidade na Administração Pública é } \\
\text { uma tarefa árdua e complexa, no entanto, a constante atuação do Ministério } \\
\text { Público, e dos próprios cidadãos, é capaz de garantir que a aplicação e a } \\
\text { administração dos recursos públicos, assim como a conduta dos agentes, } \\
\text { demonstre o interesse coletivo, como o único objetivo a ser buscado pela } \\
\text { Administração. }\end{array}$ \\
\hline
\end{tabular}

Fonte: Criado pelos autores.

O quadro 2, apresentado abaixo, nos traz a conceituação da palavra corrupção, em como esta está altamente ligada com o sentido de trapaça, falta de legitimidade nos atos, e suas consequências acarretam baixos níveis de desenvolvimento e alto índice de inadequações e degradação no modo de vida de parte da população, e no trabalho dentro das organizações. 
Quadro 2. Corrupção

\begin{tabular}{|c|c|}
\hline ESTUDO REALIZADO & RESUMO \\
\hline Brei, Z. A, (1994) & $\begin{array}{l}\text { A definição de corrupção apresentada pelo autor está ligada aos atos de } \\
\text { trapaça, ganho ilícito, fraude, mostrando que tal comportamento vai de } \\
\text { pequenos desvios à crime organizado. }\end{array}$ \\
\hline Costa, L.C. P, (2014) & $\begin{array}{l}\text { Para o autor, a corrupção traz efeitos negativos em reação à legitimidade } \\
\text { política de um Estado/País. Para ele, não são os subornos em si o que mais } \\
\text { prejudica, mas as situações, muitas vezes criadas com a finalidade do } \\
\text { alcance de propina sobre tal fato. }\end{array}$ \\
\hline Filgueiras, F. (2004) & $\begin{array}{l}\text { Sobre o conceito de corrupção, é pensado sempre nos interesses, passando } \\
\text { por cima de elementos culturais, sociais e políticos no qual o agente está } \\
\text { inserido. }\end{array}$ \\
\hline Moura, A.G. A, (2011) & $\begin{array}{l}\text { A disseminação da corrupção no Estado brasileiro é apontada como } \\
\text { consequência da dissociação que se verifica entre a ética e a política, } \\
\text { partindo daqueles que ocupam o poder estatal, em desprezando questões } \\
\text { éticas e sociais em prol da satisfação do interesse privado. }\end{array}$ \\
\hline Nucci, S.G. D, (2015) & $\begin{array}{l}\text { A corrupção para o autor se caracteriza pela negociação, pelo acordo ilícito, } \\
\text { depravação moral, gerando muitas vezes estragos consideráveis ao Estado. } \\
\text { Não se limita à Administração Pública, pois há também em organizações } \\
\text { particulares e privadas. Algumas destas que se auto intitulam corretas e } \\
\text { honestas, ora são surpreendidas com a imensa podridão derivada de } \\
\text { negócios malvistos e ilegais. }\end{array}$ \\
\hline Pereira, J.M, (2005) & $\begin{array}{l}\text { O autor traz que corrupção não é algo que acontece em uma sociedade } \\
\text { como um desastre natural. Para esse autor, trata-se da atividade de pessoas } \\
\text { e grupos reais que traficam influências em um dado ambiente de } \\
\text { oportunidades, de recursos e de limitações. }\end{array}$ \\
\hline Rocha, L.R. R, (2016) & $\begin{array}{l}\text { O artigo de Rocha visa mostrar que as consequências da corrupção vão } \\
\text { além do efeito concreto e imediato do ato praticado e que países que } \\
\text { apresentam altos índices de percepção de corrupção, em geral, sofrem com } \\
\text { baixos indicadores sociais. }\end{array}$ \\
\hline $\begin{array}{l}\text { Simioni, R.L; Miranda, } \\
\text { (2007) }\end{array}$ & $\begin{array}{l}\text { O autor apresenta que a corrupção, que pode ser vista como um problema } \\
\text { de governança e ser observado como um problema moral, ético e religioso. }\end{array}$ \\
\hline Tanzi, V, (1998) & $\begin{array}{l}\text { O autor em sua publicação diz que a corrupção não é expressa somente em } \\
\text { pagamentos de suborno, mas também quando um funcionário público } \\
\text { afirma estar doente e mesmo assim sai de férias, abusando assim de seu } \\
\text { poder público em benefício próprio. }\end{array}$ \\
\hline Zanini, J.C, (2014) & $\begin{array}{l}\text { Classifica o problema da corrupção na impossibilidade humana de perceber } \\
\text { o outro e o bem comum, como um desvio de caráter, que nem sempre } \\
\text { ocorre conscientemente, e por completa compreensão das validades } \\
\text { morais estabelecidas. }\end{array}$ \\
\hline
\end{tabular}

Fonte: Criado pelos autores. 


\section{DISCUSSÃO}

De acordo com todo o conteúdo elencado ao longo deste artigo, com as análises e observações acerca do tempo proposto, sabe-se que, a corrupção, uma das faces da improbidade, é um fenômeno social que se desenvolve com muita rapidez no Brasil e no mundo. Este não é um fenômeno atual, existe há muito tempo em nossa sociedade histórica. Assim, como podemos observar no Quadro 2, pode se compreender o motivo de estes assuntos serem tão buscados e comentados no Brasil e no mundo, motivo esse que deriva de tantos escândalos da política brasileira no cenário atual.

Este cenário com os altos índices de corrupção demonstra as aberturas de práticas ilícitas iniciadas há muito tempo atrás, estendendo-se nos longos anos de ditadura e perdurando até os dias atuais.

Reiterando o conceito, a improbidade é um fato presente durante toda a nossa história, podendo ser combatida ou não, partindo de cada ser envolvido com a administração, sendo punitiva para todos aqueles que praticarem $o$ ato de se beneficiar dos recursos que foram retirados de uma parcela maior que seria usada para o bem de toda uma população.

O conceito de improbidade estando atrelado ao conceito de moralidade administrativa descreve atos onde os agentes públicos e o próprio Ministério Público estão envolvidos com a imoralidade, demonstrada de formas como o enriquecimento ilícito, o mal uso de recursos públicos, uso de favores em troca de propina ou benefício de terceiros. A Lei 8.429/92 está à disposição para uso de condenação de tais infratores, e assim, garantir que o que é para ser usado em busca de melhorias para o bem comum, seja de fato usado por todos aqueles no qual deveriam estar sendo favorecidos perante a Constituição Federal.

Nesse processo, o Brasil e suas instituições necessitam estar voltados para um melhor crescimento socioeconômico. E para salientar e alcançar esse objetivo, é de extrema importância assegurar a aplicação e a interpretação das leis de forma mais rigorosa, sem privilégios, visando gradativamente, a extirpação da sensação de impunidade, com a qual estamos habituados no Brasil.

\section{CONCLUSÃO}

O estudo atingiu seu objetivo ao realizar uma revisão integrativa dos principais estudos que compõem a temática de improbidade administrativa e corrupção, delineando um novo caminho a ser tomado na academia.

Além disso, conclui-se este estudo com o entendimento de que sempre houve e haverá a Improbidade e a Corrupção, mas que por meios éticos, morais e jurídicos, como a Lei 8.429/92, possa amenizar e se possível erradicar os meios e as consequências destes dois problemas encontrados em nossa sociedade.

Portanto, reitero nesta nossa contribuição sobre os assuntos acima mencionados e, estimase que este possa servir na busca por melhorias na presente situação social, moral e, econômica das organizações, tanto no Brasil quanto no mundo inteiro.

Como limitações do estudo podem-se apontar o não aprofundamento nos artigos em diferentes bases de dados internacionais, assim como na divisão dos estudos segundo as áreas de interesse. Para estudos futuros, propõe-se que ampliar o olhar sobre a esfera internacional, e utilizem de outras palavras-chave para sua busca em novas bases de dados.

\section{REFERÊNCIAS}

ARAÚJO, R. E. Os principais aspectos da lei de improbidade administrativa. 16 f. 2009. Procuradora Federal junto à Procuradoria Federal em Santa Catarina. 
BRASIL. LEI No 8.429, DE 2 DE JUNHO DE 1992. Lei de Improbidade Administrativa. Disponível em: <http://www.planalto.gov.br/Ccivil_03/leis/L8429.htm>. Acesso em: 22 de mar. 2018.

BREI, Z. A. Corrupção: dificuldades para definição e para um consenso. Rio de Janeiro, 1994.

BOTELHO, L. L. R.; CUNHA, C. C. A.; MACEDO, M. 0 método da revisão integrativa nos estudos organizacionais. Belo Horizonte: UFMG, 2011.

CAVALCANTI, P. R. A. A corrupção no Brasil. São Paulo: Siciliano, 1991, p.17.

COSSATIS, R. C. Os agentes políticos e a Improbidade Administrativa. Rio de Janeiro, 2010.

COSTA, A. M. A. A Interpretação do Princípio da Moralidade Administrativa em Relação ao Princípio da Legalidade Administrativa, Juína: AJES, 2013.

COSTA, H. P. Corrupção e Improbidade Administrativa, Revista do Ministério Público: Alagoas, n. 15, jan./jun. 2005.

Disponível em < http://www.egov.ufsc.br/portal/sites/default/files/anexos/15970-15971-1PB.pdf>

COSTA, L. C. P. Improbidade administrativa: não realização de estudo de impacto ambiental para obras públicas. Manaus: Universidade do Estado Amazonas, 2014. 133 fls.: 30.

CRIVELLARO, Gustavo. Improbidade administrativa. LFG, [S.I.], 2002. Disponível em: <http://www.egov.ufsc.br/portal/sites/default/files/anexos/20064-20065-1-PB.pdf> acesso em abr. 2018

FIGUEIREDO, M. Probidade Administrativa, São Paulo: Malheiros Editores, 1995.

FILGUEIRAS, F. Notas Críticas Sobre o Conceito de Corrupção. In: Teoria e Sociedade, vol. 12, no 1, 2004.

FONSECA, J. J. S. Metodologia da pesquisa científica. Fortaleza: UEC, 2002.

FRANÇA, V. R. Considerações sobre o controle de moralidade dos atos administrativos. Revista Trimestral de Direito Público, São Paulo, n. 27, p.58-74, 1999.

FREITAS, J. Do princípio da probidade administrativa e de sua máxima efetivação. Revista de Direito Administrativo. Rio de Janeiro, v. 204, p. 65-84, jan. 1996. ISSN 2238-5177. Disponível em: <http://bibliotecadigital.fgv.br/ojs/index.php/rda/article/view/46754/46380>. Acesso em: 22 Mar. 2018. doi: http://dx.doi.org/10.12660/rda.v204.1996.46754. 
GARCIA, E. Improbidade administrativa. 8.ed. São Paulo: Saraiva, 2014

GIL, A. C. Métodos e técnicas de pesquisa social. 5.ed. São Paulo: Atlas, 2007.

LAKATOS, E. M.; MARCONI, M. A. Técnicas de Pesquisa. 5.ed. São Paulo: Atlas, 2007.

MARCONI, M. A.; LAKATOS, M. E. Metodologia do Trabalho Científico, 8.ed. São Paulo: Atlas, 2017.

MORAES, A. Direito constitucional. 28.ed. São Paulo: Atlas, 2012.

MOURA, A. G. A Atuação do Ministério Público no Combate à Corrupção: Oportunidade de Resgate da Cidadania. Revista da Faculdade Mineira de Direito, v.12, n. 23, jan./jun. 2011.

MOURA, C. C. S. Aspectos relevantes sobre a Improbidade Administrativa, Lei 8.429/92. In: Âmbito Jurídico. Rio Grande, XVII, n. 125, jun. 2014. Disponível em: <http://ambitojuridico.com.br/site/?n_link=revista_artigos_leitura\&artigo_id=14131>. Acesso em 22 Mar. 2018.

NUCCI, S. G. D. Corrupção e Anticorrupção. Rio de Janeiro: Forense, 2015

PAIÉ, K. S. N. Presunção de enriquecimento ilícito na Lei de improbidade administrativa. In: Âmbito Jurídico, Rio Grande, XIV, n. 86, mar 2011. Disponível em:

<http://www.ambitojuridico.com.br/site/index.php?n_link=revista_artigos_leitura\&artigo_id=909 7>. Acesso em 23 Abr. 2018.

PAZZAGLINI F. M.; ROSA, M. F. E.; FAZZIO JR., W. Improbidade administrativa. 4.ed. São Paulo: Atlas, 1999.

PEREIRA, J. M. Reforma do Estado e controle da corrupção no Brasil. Caderno de Pesquisas em Administração, São Paulo, v. 12, n. 2, p. 1-17, 2005.

PIMENTEL, I. A. A Corrupção no Brasil e a atuação do Ministério Público. João Pessoa: UFPB, 2014.

RICHARDSON, R.J. Pesquisa social: métodos e técnicas. 3 Ed., São Paulo: Atlas, 2007.

ROCHA, L. R. R. Corrupção: os efeitos deletérios sobre as políticas de saúde. Universitas Jus, Brasília, v. 27, n. 3, 2016.

SILVA, J. A. Curso de direito constitucional positivo. 35.ed. São Paulo: Malheiros, 2012. 
SIMIONI, R. L.; MIRANDA. Direito, silêncio e corrupção: um diálogo com Niklas Luhmann e Jürgen Habermas. In: Âmbito Jurídico, Rio Grande, X, n. 40, abr 2007. Disponível em:

http://www.ambitojuridico.com.br/site/index.php?artigo_id=4103\&n_link=revista_artigos_leitura >. Acesso em 22 Mar. 2018.

TANZI, V. Corruption Around the World: Cause, Consequences, Scope, and Cures. EUA, 1998.

WAICK, F. A. L. O Princípio Da Moralidade Administrativa E A Lei De Improbidade Administrativa, Rio Grande do Sul: PUCRS, 2009.

ZANINI, J. C. Corrupção Administrativa e Mecanismos de Controle Externo: Discussão doutrinária principiológica. Itajaí: UNIVALI, 2014. 